\title{
Effect of the Jendrassik manoeuvre on a phasic stretch reflex in normal human subjects during experimental control over supraspinal influences
}

\author{
ALEX M. CLARKE \\ From the Department of Psychology, Australian National University, Canberra, A.C.T. (Australia)
}

\begin{abstract}
Until recently the evidence gained by comparisons between electrical ( $\mathrm{H}$ reflex) and mechanical (tendon jerk) stimulation during the Jendrassik manoeuvre has indicated that the fusimotor (gamma efferent) system plays the paramount role in facilitating monosynaptic reflexes by heightening the sensitivity of the muscle spindles. More recent evidence, making use of the same techniques, has raised the question that it may not be necessary to postulate facilitation during the Jendrassik manoeuvre solely to be the result of fusimotor biasing of the spindle. This report deals with experiments which examine this question by studying the effects of the Jendrassik manoeuvre during several conditions (other than electrical stimulation) designed to control supraspinal influences differentially.
\end{abstract}

Landau and Clare (1964), in the introduction to their article, have pointed out that the use of the Hoffmann technique of electrical stimulation of muscle afferents, by which the effect of the spindle receptor may be isolated from the motor response, has enabled investigators to infer that the facilitation of monosynaptic reflexes during the Jendrassik manoeuvre occurred by way of fusimotor alteration of the sensitivity of the spindle. The $\mathrm{H}$ reflex seemed resistant to augmentation during the manoeuvre (Buller and Dornhorst, 1957; Paillard, 1959) and it was reasonable to assume that the fusimotor neurones, which exclusively innervate the intrafusal fibres of the spindle (Kuffler, Hunt, and Quilliam, 1951), were responsible for the augmentation phenomenon.

Since 1961 there have been reports of the augmentation of the $H$ reflex by contraction of remote muscles (Benson and Gedye, 1961; Landau and Clare, 1964). In addition, Clare and Landau (1964) have used the technique of differential nerve blockade (Matthews and Rushworth, 1957) to study the effect of the Jendrassik manoeuvre on reflexes

${ }^{1}$ Commonwealth postgraduate research scholar which had been depressed by the selective blockade of tonic fusimotor discharge. They found that augmentation of the reflex became more effective and 'when the tendon jerk was absent, even with reinforcement, the depressed $\mathrm{H}$ reflex could still be reinforced'.

If the sensitization of the spindle by way of the fusimotor system is not the sole facilitating mechanism during the Jendrassik manoeuvre, what additional influences could be operating?

Sensory pathways make collateral connexions with the reticular formation (Magoun, 1958) so that ascending impulses from activity in remote muscles during the manoeuvre would be expected initially to activate the reticular formation which has direct and comprehensive connexions with fusimotor neurones (Granit and Kaada, 1953; Appelberg and Emonet-Denand, 1965). Therefore, the level of excitation of the reticular formation is likely to be mirrored in the excitation of fusimotor neurones (Granit, 1957) and, consequently, in the threshold of the spindles. However, descending influences not only affect alpha motor neurone response indirectly by way of the fusimotor neurones but also partly by direct potentiation of alpha spinal cells (Rossi and Zanchetti, 1957). Presumably in normal subjects, both these modes of influence operate together on the alpha response (Granit, Pompeiano, and Waltman, 1959) when the reticular system is aroused by afferent impulses emanating from active contraction of remote muscles during the Jendrassik manoeuvre.

Since some degree of fusimotor tone probably is necessary for the existence of a stretch reflex (Eldred, 1960) and as the fusimotor neurones constantly fluctuate (Granit and Henatsch, 1956), the biasing of the spindle would be expected to contribute increased variability of response. There is some evidence to show that a reliable, indirect indication of fusimotor activity in human subjects is the 
variability of the diphasic muscle action potential recorded from surface electrodes during a phasic stretch reflex (Clarke, 1965b; 1966). The data graphed by Benson and Gedye (1961, p. 45, Fig. VIII) support this proposition; there is a significant difference between the mean amplitude of reflex response for both the tendon jerk and the $\mathrm{H}$ reflex (p $<0.001,18$ d.f.; each statistic was the mean of eight observations for four subjects) between control trials and trials when a remote muscle was contracted. However, the $F$ ratio was significant only for the tendon jerk which is consistent with the proposition that heightened fusimotor activity results in increased variability of the reflex response.

In the experiments reported here, the effect of the Jendrassik manoeuvre on the patellar reflex was investigated under several conditions in the expectation that each condition would lead to fusimotor discharge having a differential effect on the response. The four experiments consisted of a comparison of the reflex responses in the following pairs of conditions:-

(1) Control, with the subject relaxing, and a Jendrassik manoeuvre maintained for $1 \mathrm{sec}$. before the tap on the ligamentum patellae; (2) control and a Jendrassik manoeuvre maintained for $10 \mathrm{sec}$; (3) active contraction of the rectus femoris (prestrain) and pre-strain with concurrent execution of a Jendrassik manoeuvre for $1 \mathrm{sec}$.; and (4) control and Jendrassik manoeuvre $(1 \mathrm{sec}$.) in a series of sessions designed to investigate the effect of an interneuronal blocking agent, Myanesin (Mephenesin, B.P.C.).

The reasons for these procedures were as follows:

Fusimotor discharge is related to change in degree of alertness or activation (Buchwald and Eldred, 1961) and therefore the subjects were trained in mental and physical relaxation, using Jacobson's method (1924). It was anticipated that the maintenance of a consistent level of relaxation would be conducive to reduced fusimotor discharge and, consequently, to reflex responses having small variability about the mean. This would enable clear comparisons to be made between control and experimental results.

Bowditch and Warren (1890) have reported that the augmentation of the patellar reflex was lost if the Jendrassik manoeuvre was continued for more than 2 sec. although Buller and Dornhorst (1957) found that reinforcement persisted up to $6 \mathrm{sec}$. Since neurones in the mesencephalic reticular formation are known to respond well to initial sensory stimulation but to attenuate to repetitive stimuli (Bell, Sierra, Buendia, and Segundo, 1964), it may be assumed that a Jendrassik manoeuvre would result in ascending impulses which would initially augment the reticular response but if the Jendrassik manoeuvre were continued, reticular neurones would become adapted. These features of reticular response would be paralleled, as a result of direct and indirect descending influences, by similar characteristics of alpha motor neurone response. That is, both the amplitude and variability of the motor response should be increased during the Jendrassik manoeuvre $(1 \mathrm{sec}$.) conditions but these aspects of the response during the manoeuvre $(10 \mathrm{sec}$.) conditions should not be different from control responses.

During active, isometric contraction of the rectus femoris muscle the spindles would be unloaded because it is thought that the tendons are elastic enough to permit some shortening of the extrafusal fibres (Eldred, Granit, and Merton, 1953). Therefore, the tap on the ligament was timed to occur just as the subject brought the force up to the required amount of pre-strain, the assumption being that the response would be elicited before the fusimotor system, which would become active when voluntary contraction began, could adjust the slack in the intrafusal fibres to the new length of the extrafusal fibres. Under these circumstances, the effect of fusimotor biasing would be minimized and a decrease in variability of response compared with control would be expected. Also, if the increased sensitization of the spindle by fusimotor activity were the main source of influence, no significant augmentation should occur between pre-strain trials and pre-strain with trials of the Jendrassik manoeuvre.

Myanesin was used because it acts rapidly to reduce supraspinal influences whilst leaving the monosynaptic (stretch reflex) pathways unaffected (Berger, 1947, 1949; Voorhoeve, 1960; Sink, 1965). Also, the drug is known to depress bulbo-reticular facilitation of the patellar reflex and fusimotor excitation of spindles (Domino, 1956). The expectation was that both the direct and indirect descending influences would be attenuated and, therefore, the Jendrassik manoeuvre should have no effect on amplitude or variability of response compared with control reflexes during the peak drug effect.

\section{SUBJECTS AND METHODS}

Normal subjects (two males, two females) were studied during the main experiments. One male and one female participated in the pre-strain experiments and two females in the drug experiments.

All experiments were conducted in a sound-proofed, electrically shielded, and air-conditioned room (Clarke, 1965a). The subjects were seated in a chair with supports for head, arms, and thighs. The reflex was elicited with a pendulum hammer which had a strain gauge mounted in the head to permit measurement of the force of the tap on the ligament. The hammer was screened from the 
subject's view and was dropped from a constant height within sessions. Hence, if muscle tone did not change, the force of the tap would be similar from trial to trial and, therefore, results were not used unless statistical tests between means within sessions showed that no significant difference in force existed between treatments.

A Statham bi-directional trandsucing cell (model UC 2) and load cell accessory (model UL4-20) were attached securely to the chair and linked to the cuff which restrained the subject's ankle to permit measurement of the force of the isometric reflex contraction.

Hollow disk silver electrodes were applied 3.75 in. apart over the belly of the rectus femoris and hamstring muscles to receive muscle action potentials. A ground strap was placed around the upper thigh.

Electrical potentials were pre-amplified through pushpull circuitry at a gain of $2.5 \mathrm{k}$ (response $3 \mathrm{db}$ down at $1.5 \mathrm{c} / \mathrm{s}$ ) and fed to a pen recorder of flat response up to $75 \mathrm{c} / \mathrm{s}$. The pre-amplifier and DC amplifier system was calibrated by delivering a signal of known voltage at the electrodes. All E.M.G. and force signals were recorded on paper using a Both recorder at a speed of $50 \mathrm{~mm}$. $/ \mathrm{sec}$.

Latency observations (defined as the time from the instant the pendulum hammer struck the skin over the ligamentum patellae to the initiation of the first synchronous muscle action potential in the rectus femoris) were possible for three subjects.

The force of the tap on the ligament was adjusted before each experiment began so that it was barely over the threshold necessary to elicit a reflex. The maximum force of the tap was of the order of $1.62 \mathrm{~kg}$. (range, 1.01 to $2.66 \mathrm{~kg}$.) and the interval between taps was at least $15 \mathrm{sec}$.

Variations exist between and within days in the threshold of the patellar reflex and therefore only within-sessions comparisons were made between conditions. Typical sessions consisted of a counterbalanced design of five control trials, 10 experimental trials, and five control trials. Sessions also were conducted to test for possible effects of the sequence of presentation on the results.

The type of Jendrassik manoeuvre used was $15 \mathrm{~kg}$. force exerted by both hands with dynamometers.

During the pre-strain trials, the subject observed a meter which registered the force at the ankle cuff and reported to the investigator so that the ligament could be tapped as the required force was reached. Trials which did not meet this criterion were discarded.

The drug experiments consisted of (1) a counterbalanced design to compare control and Jendrassik manoeuvre (1 sec.) responses, (2) pre-drug, post-drug $\left(\frac{1}{2} \mathrm{hr}\right.$.) and post-drug ( $1 \frac{1}{2} \mathrm{hr}$.) sessions, and (3) identical sessions to those in (2) except that a placebo (calcium carbonate) was given to test for possible pseudo effects. Dosage was $1 \mathrm{gr}$. taken orally. There were no adverse drug effects and tests for nystagmus were negative.

The impulse (integral of voltage and time) of the muscle action potential was used as the principal dependent variable and was quantified by visually measuring the area between the diphasic record and the axis in $\mu \mathrm{V}$ sec. Two-tailed t tests of the difference between means of control and Jendrassik conditions were used to evaluate augmentation of the reflex whilst $F$ ratio tests between variances served as an indication of fusimotor activity.

\section{RESULTS}

AUGMENTATION AND ADAPTATION Without exception for the four subjects there was a significant increase in mean impulse of the muscle action potential for the Jendrassik manoeuvre (1 sec.) conditions, whilst there was no significant increase in mean amplitude during the conditions of the Jendrassik manoeuvre (10 sec.). Table I gives data for subject M.D. and Fig. 1 shows examples of the simultaneous E.M.G. and force records for the control and two Jendrassik conditions for subject B.H. High positive correlations were observed between electrical and mechanical responses (Figs. 2 and 3 and Table I).

A significant increase in the variability of the impulse of the muscle action potential between control and Jendrassik conditions at $1 \mathrm{sec}$. but no increase during conditions at $10 \mathrm{sec}$. was observed without exception. Similar results were obtained for the maximum force of the isometric contraction (Table I).

TABLE I

DATA FOR TWO ASPECTS OF THE PATELLAR REFLEX RESPONSE DURING THE JENDRASSIK MANOEUVRE IN SUBJECT M.D.

Impulse of the Muscle Action Potential Maximum Force of the Isometric (Rectus Femoris) ( $\mu$ V sec.) Contraction at the Ankle (kg.)

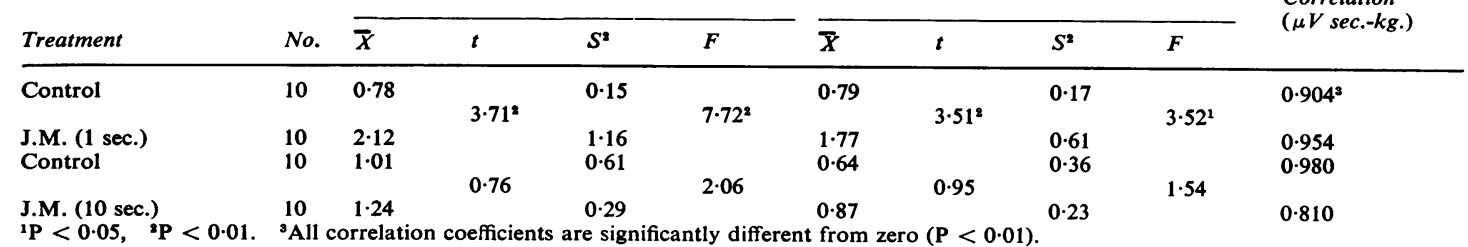

Pearson's

Product-Moment

Correlation

$\mu \mathrm{Vec} . \mathrm{kg}$.

IP $<0.05$, "P $<0.01$. ${ }^{3}$ All correlation coefficients are significantly different from zero $(\mathbf{P}<0.01)$ 

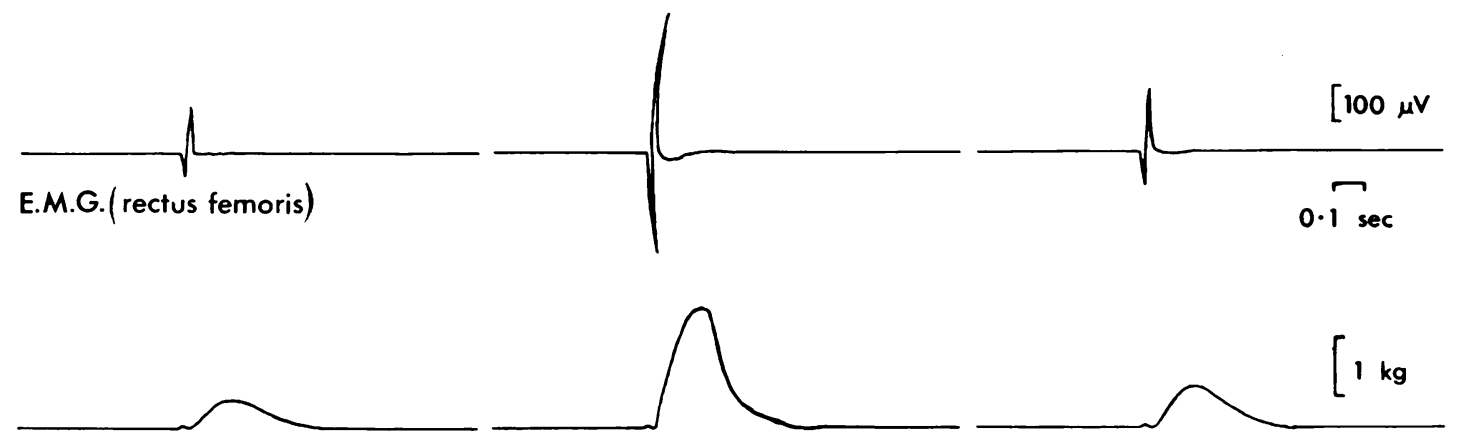

myogram (impulse of isometric contraction)

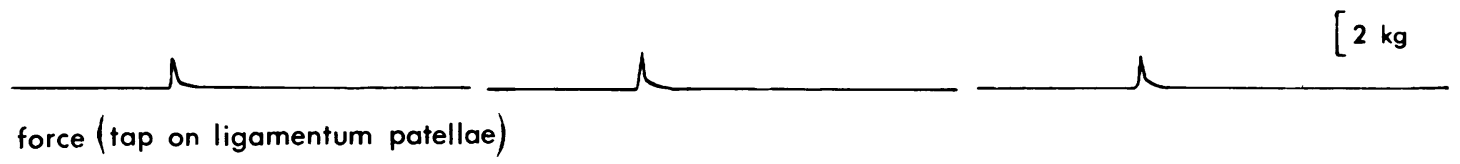

$20 \cdot 5$

$18 \cdot 5$

$20 \cdot 0$

latency ( $\mathrm{msec})$

FIG. 1. Electromyograms, force, and latency records of the isometric response (patellar reflex) during a control trial (left), a Jendrassik manoeuvre for 1 sec. (middle) and a Jendrassik manoeuvre for $10 \mathrm{sec}$. (right). The E.M.G. from hamstring muscle was monitored to be sure the muscle did not become active and modify the extensor response. Subject B.H.

PRE-STRAIN The results showed that a significant increase in mean impulse of the muscle action potential was obtained between pre-strain and prestrain with the Jendrassik manoeuvre (1 $\mathrm{sec}$.)

\section{TABLE II}

TYPICAL DATA FOR PRE-STRAIN EXPERIMENTS IN SUBJECT B.H.

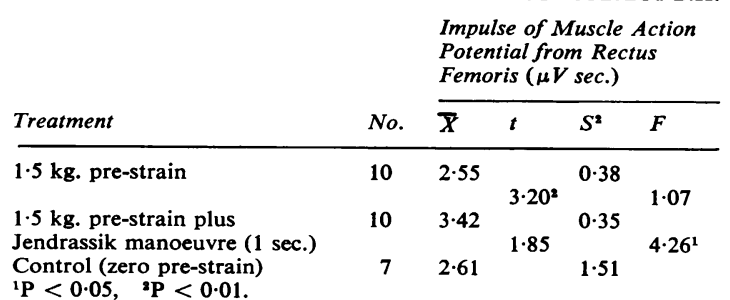

conditions (Fig. 4); no differences existed between the variances of the two conditions, and there was a significant decrease in variability between control and each of the two pre-strain conditions. Table II gives data for subject B.H.

INTER-NEURONAL BLOCKADE Table III gives data relevant to the drug and placebo sessions for subject M.D. The pre-drug, post-drug $\left(1 \frac{1}{2} \mathrm{hr}\right.$.), and all placebo sessions yielded significance test results similar to those for comparisons of Jendrassik manoeuvre (1 sec.) and control conditions in Table I. There was no placebo effect. Post-drug $\left(\frac{1}{2} \mathrm{hr}\right.$.) sessions showed that the Jendrassik manoeuvre failed to augment the reflex nor did it increase the variability compared with the control. 


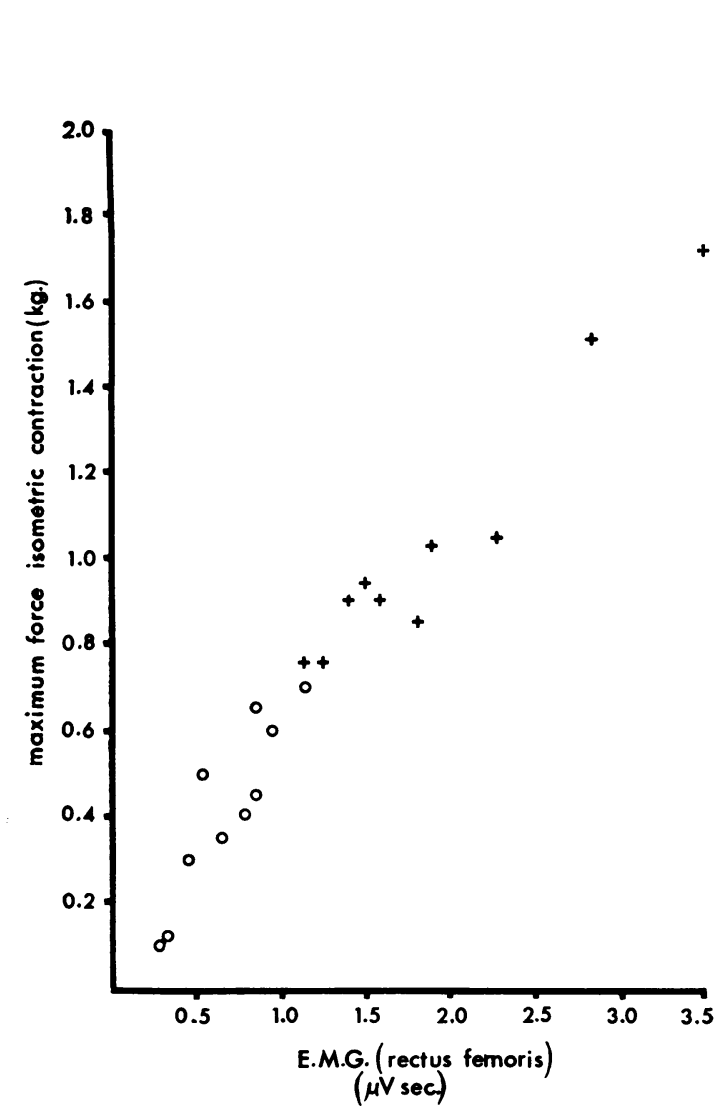

FIG. 2. Graph to show the relationship between the maximum force of the isometric contraction and the impulse of the muscle action potential from the rectus femoris in the patellar reflex. Control $0(r=0.892)$, Jendrassik manoeuvre $(1 \mathrm{sec}$. $)+(r=0.968)$. Subject B.H.

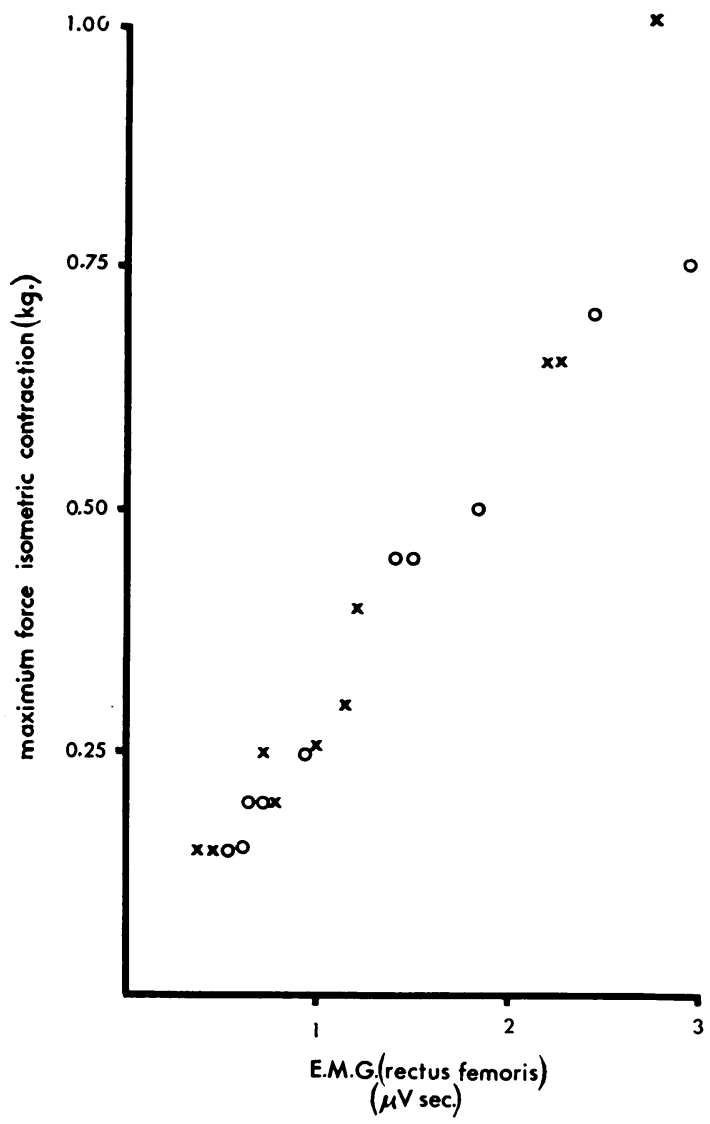

FIG. 3. Graph to show the relationship between the maximum force of the isometric contraction and the impulse of the muscle action potential from rectus femoris in the patellar refiex. Control $0(r=0.982)$, Jendrassik manoeuvre (10 sec.) X $(r=0.957)$. Subject B.H.

TABLE III

DATA FOR DRUG AND PLACEBO EXPERIMENTS IN SUBJECT M.D.

Impulse of Muscle Action Potential from Rectus Femoris ( $\mu$ V sec.)

\begin{tabular}{|c|c|c|c|c|c|c|c|c|c|c|c|}
\hline \multicolumn{2}{|c|}{ Pre-drug } & \multicolumn{2}{|c|}{ Post-drug ( $\left.\frac{1}{2} h r.\right)$} & \multicolumn{2}{|c|}{ Post-drug ( $1\lfloor h r)}$. & \multicolumn{2}{|c|}{ Pre-placebo } & \multicolumn{2}{|c|}{ Post-placebo ( $\left.\frac{1}{2} h r.\right)$} & \multicolumn{2}{|c|}{ Post-placebo $\left(I_{\frac{1}{2}} h r.\right)$} \\
\hline Control & $\begin{array}{l}J . M . \\
\text { (I sec.) }\end{array}$ & Control & $\begin{array}{l}\text { J.M. } \\
\text { (1 sec.) }\end{array}$ & Control & $\begin{array}{l}\text { J.M. } \\
\text { (I sec.) }\end{array}$ & Control & $\begin{array}{l}J . M . \\
\text { (1 sec.) }\end{array}$ & Control & $\begin{array}{l}\text { J.M. } \\
\text { (1 sec.) }\end{array}$ & Control & $\begin{array}{l}\text { J.M. } \\
\text { (I sec.) }\end{array}$ \\
\hline $\begin{array}{l}10 \\
1.08\end{array}$ & $\begin{array}{l}10 \\
5 \cdot 81\end{array}$ & $\begin{array}{l}10 \\
5 \cdot 29\end{array}$ & $\begin{array}{l}8 \\
4 \cdot 19\end{array}$ & $\begin{array}{l}10 \\
1 \cdot 31\end{array}$ & $\begin{array}{l}10 \\
3 \cdot 75\end{array}$ & $\begin{array}{l}10 \\
1.62\end{array}$ & $\begin{array}{l}10 \\
8.04\end{array}$ & $\begin{array}{l}10 \\
1 \cdot 35\end{array}$ & $\begin{array}{l}10 \\
6 \cdot 54\end{array}$ & $\begin{array}{l}10 \\
1 \cdot 60\end{array}$ & $\begin{array}{l}10 \\
7 \cdot 53\end{array}$ \\
\hline 0.507 & 3.97 & 10.59 & 6.49 & $\begin{array}{ll}0.31 & \\
& 8\end{array}$ & $2 \cdot 76$ & 0.84 & $4^{1} 3 \cdot 81$ & $0.77^{6}$ & $6^{3} 4 \cdot 58$ & $1.44^{8}$ & $3 \cdot 2$ \\
\hline 21.5 & $19 \cdot 4$ & 1.63 & $20 \cdot 3$ & $22 \cdot 8$ & $20 \cdot 2$ & $21 \cdot 2$ & $19 \cdot 3$ & \multicolumn{2}{|c|}{$\begin{array}{r}5.96^{2} \\
19 \cdot 3\end{array}$} & \multicolumn{2}{|c|}{$\begin{array}{ll}2 \cdot 23 & \\
& \end{array}$} \\
\hline
\end{tabular}

(msec.)

${ }^{1} \mathrm{P}<0.05, \quad{ }^{2} \mathrm{P}<0.01$, and ${ }^{3} \mathrm{P}<0.001$. 

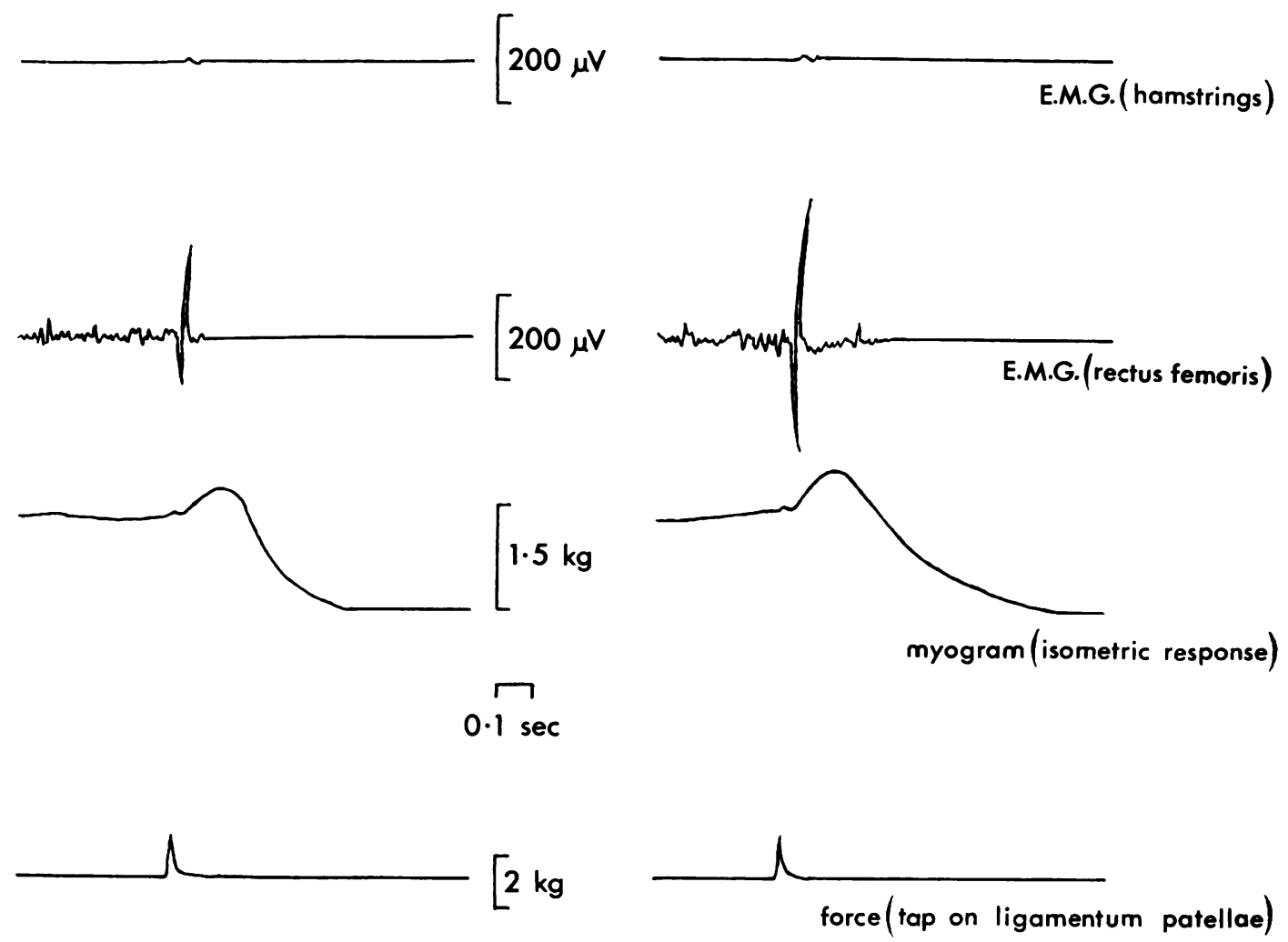

A

FIG. 4. Electromyogram and force records of the isometric response for the patellar reflex during (A) pre-strain of $1.5 \mathrm{~kg}$. force at the ankle cuff before the tap on the ligamentum patellae and $(B)$ pre-strain of $1.5 \mathrm{~kg}$. and a concurrently executed Jendrassik manoeuvre (1 sec.). The amplitude of the response is augmented by the Jendrassik manoeuvre. Subject B.H.

REFLEX LATENCY The general finding for the subjects was that latency was reduced significantly by the Jendrassik manoeuvre $(1 \mathrm{sec}$.) conditions but no reduction in latency occurred during conditions at $10 \mathrm{sec}$. compared with control responses (Fig. 5). During the peak effect of the inter-neuronal blocking agent, no difference in latency between control and Jendrassik manoeuvre (1 sec.) trials was observed (Table III). Some examples of mean latency observations between various conditions for subject M.D. are given in Table III. Latency observations were not possible with the apparatus used, during prestrain conditions.

\section{DISCUSSION}

These experiments confirm previous evidence (Varnum, 1934; Buller and Dornhorst, 1957;
Benson and Gedye, 1961; Rabending and Koch, 1962) for the strong facilitation of the motor neurones supplying the extensor muscle in a phasic stretch reflex when the Jendrassik manoeuvre is initiated less than $1 \mathrm{sec}$. before the reflex is elicited by a tendon tap. Augmentation was found within a range of muscle tonus (provided tonus was constant between experimental conditions within sessions) from normal resting tension to $1.5 \mathrm{~kg}$. pre-strain, measured at the ankle. Prolonged execution of the Jendrassik manoeuvre or the absorption of an interneuronal blocking agent resulted in the loss of augmentation.

These differential effects cannot be attributed to peripheral influences such as alteration in muscle length as a result of change in muscle tone. The pendulum hammer was dropped from a uniform height within sessions and no significant difference 


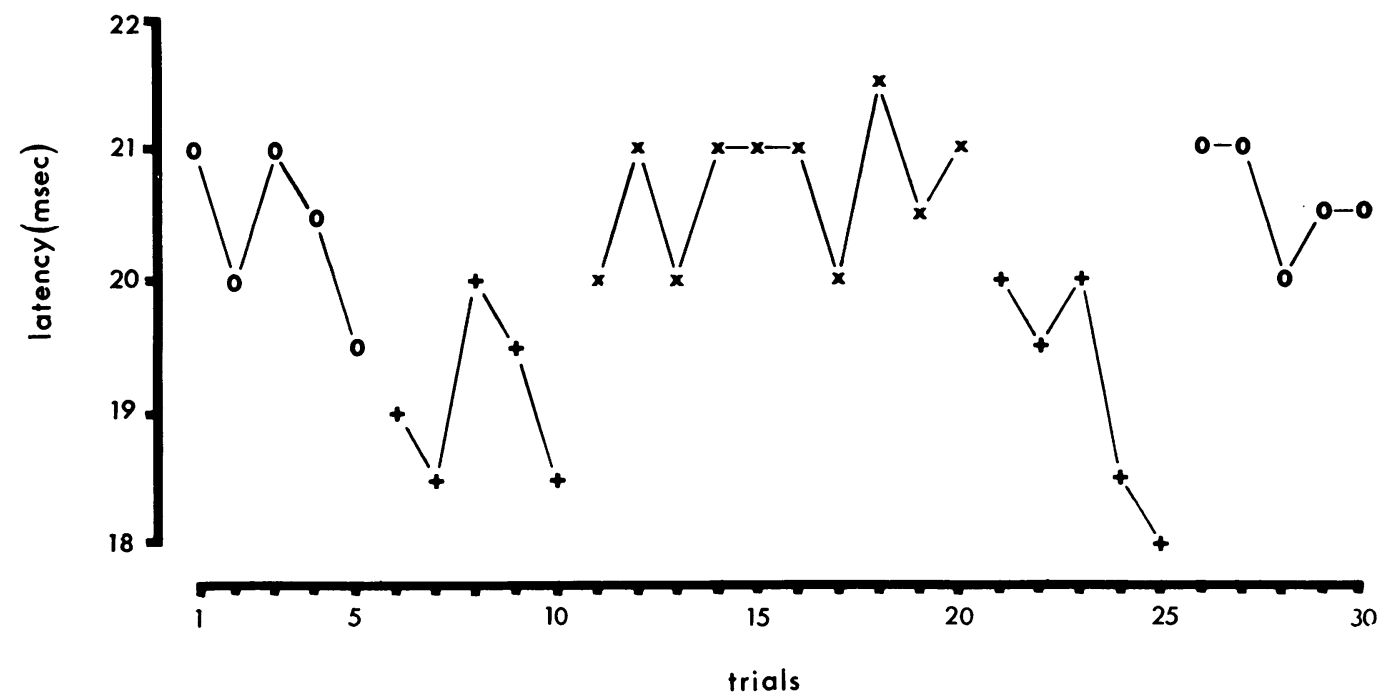

FIG. 5. Graph of data from a counterbalanced experimental design to show the decrease in latency $(P<0.001)$ for the patellar reflex during Jendrassik manoeuvre $(1$ sec.) trials $(+)$ compared with control trials $(0)$, whilst Jendrassik manoeuvre (10 sec.) trials $(X)$ are not different from control (Student's $t=0 \cdot 89.18$ d.f.). Subject B.H.

existed between the mean peak force on the ligament between control and experimental conditions. Therefore, it may be assumed that the rate and amount of extension of extrafusal fibres was similar from trial to trial and no change in frequency of discharge or number of muscle stretch receptors responding could occur without central influence.

Under normal experimental conditions, a generalized arousal of reticular neurones probably occurs when a Jendrassik manoeuvre initially is begun and this results in the raised excitability of alpha and gamma motor neurones. Continued execution of the Jendrassik manoeuvre presumably results in adaptation of activity in the reticular formation so that descending impulses are attenuated; in these circumstances alpha and gamma motor neurones display no more excitability than is usual during relaxed conditions. The separate effects of direct and indirect descending pathways may be distinguished in the pre-strain experiments. It may be assumed that the influence of the fusimotor regulation of spindle sensitivity is removed to a substantial degree, and, since a briefly executed Jendrassik manoeuvre still augments the reflex, direct facilitation of alpha motor neurones seems a reasonable assumption. In the drug experiments, the inhibitory action of Myanesin on basal ganglia and nuclei of the brain-stem would counteract excitatory activity in the reticular formation (Berger, 1949). This action would reduce both the direct and indirect descending influences on the reflex and the lack of augmentation of amplitude during the Jendrassik manoeuvre seems to confirm this assumption.

Analysis of data about the variability of the reflex (as a probable indicator of fusimotor activity) lends support to the propositions put forward. When experimental manipulations do not interfere with fusimotor regulation of the spindles, Jendrassik manoeuvre $(1 \mathrm{sec}$.) conditions presumably activate the fusimotor system with consequent increased variability of the reflex response. On the other hand, Jendrassik manoeuvre $(10 \mathrm{sec}$.) conditions would be expected to result in adaptation of the fusimotor system so that reflex responses would be no different in variability from control responses. The results confirm these predictions (Table I). Unloading the spindles during pre-strain trials, thus attenuating fusimotor influence, resulted in no increase in variance during the Jendrassik manoeuvre (Table II). Likewise, the variability of control and Jendrassik manoeuvre responses during fusimotor blockade by Myanesin was not dissimilar (Table III). Generally, there was an increase in variability of reflex response compared with control when fusimotor activity was thought to be exerting a pronounced effect on spindle sensitivity whilst there was no change in variability when fusimotor activity was attenuated.

Further indications of fusimotor effects may be found in latency records because biasing causes the spindle to become a more sensitive and, therefore, a faster responding receptor (Homma, Kano, and 
Takano, 1962) without any detectable change occurring in extrafusal tension (Eldred and Fujimori, 1958). Evidence from human experiments (Clarke, 1966) has shown a reduction in latency with concurrent indications of fusimotor biasing of the spindles. The present experiments confirm that when fusimotor control may be assumed, that is, in Jendrassik manoeuvre (1 sec.) trials for normal, pre-drug, post-drug ( $1 \frac{1}{2} \mathrm{hr}$.), and all placebo trials, there is a significant reduction in reflex time. Whereas, when descending pathways may be assumed to be blocked, that is, in post-drug ( $\frac{1}{2} \mathrm{hr}$.) trials, or when fusimotor discharge is assumed to be attenuated, that is, in Jendrassik manoeuvre $(10 \mathrm{sec}$.) trials, no change in latency is observed (Table III and Fig. 5). Unfortunately, the method used did not permit latency to be measured during pre-strain trials because asynchronous muscle action potentials during active contraction triggered the timer before the synchronous muscle action potential of the reflex occurred. The prediction, under pre-strain conditions, is that no change in latency would be observed in Jendrassik manoeuvre (1 sec.) trials.

The findings of these experiments support those of Landau and Clare (1964) who have found that it is not necessary to postulate that the Jendrassik manoeuvre augments the stretch reflex specifically by way of the fusimotor system. Apparently spindle biasing is not the sole facilitatory mechanism for the reflex; direct potentiation of alpha spinal cells by supraspinal influences seems to play a part.

The results also indicate that, provided control is exercised over variables likely to affect the reflex response, it is possible to investigate the findings of infra-human experiments in muscle spindle neurophysiology with normal human subjects.

\section{SUMMARY}

The use of the Hoffmann technique of electrical stimulation of muscle afferents, which enables the effect of the spindle receptor to be isolated from the motor neurone response, has led to the inference that facilitation of monosynapiic reflexes during a Jendrassik manoeuvre was the result of fusimotor sensitization of the spindle. This conclusion was reached because the $H$ reflex seemed resistant to augmentation. However, some recent investigations have shown that the $\mathrm{H}$ reflex may be facilitated and the purpose of this article is to report experiments (using methods other than electrical stimulation) which add information about the proposition put forward by Landau and Clare (1964) that it may not be necessary for augmentation during the Jendrassik manoeuvre solely to be the result of fusimotor biasing of the spindle.
Experiments were conducted with the patellar reflex using a briefly executed Jendrassik manoeuvre during (a) normal relaxation, $(b)$ active contraction of the rectus femoris (pre-strain), and (c) intake of Myanesin (an interneuronal blocking agent). The effect of a sustained Jendrassik manoeuvre during normal conditions also was investigated. These procedures were used in the expectation that there would be differential effects of descending influences on the reflex.

Significant increases in mean amplitude of reflex response were observed under Jendrassik manoeuvre (1 sec.) conditions during normal trials (together with decreased latency) and pre-stain trials. No change in amplitude or latency, compared with control, occurred during peak drug effect or when a sustained Jendrassik manoeuvre was used.

The variability of the E.M.G. during the reflex was used as an indicator of fusimotor activity. Results supported predictions: there was a significant increase in variability of the impulse of the muscle action potential during Jendrassik manoeuvre (1 sec.) trials compared with control whereas no increase in variability occurred when fusimotor activity was assumed to be attenuated during prestrain, Jendrassik manoeuvre (10 sec.), andp eak drug effect.

The findings are consistent with the hypothesis that spindle biasing is not the sole facilitatory mechanism for the phasic stretch reflex; direct potentiation of alpha spinal cells by descending influences also seems to play some role.

The author is indebted to Dr. J. R. Trotter for discussions, Dr. J. I. Hubbard (Physiology Department) for medical supervision of the subjects during the drug experiments, and the two staff and two student members of the Psychology Department who participated in the experiments. Professor C. A. Gibb kindly provided facilities in his department.

\section{REFERENCES}

Appelberg, B., and Emonet-Denand, F. (1965). Central control of static and dynamic sensitivities of muscle spindle primary endings. Acta physiol. scand., 63, 487-494.

Bell, C., Sierra, G., Buendia, N., and Segundo, J. P. (1964). Sensory properties of neurons in the mesencephalic reticular formation. J. Neurophysiol., 27, 961-987.

Benson, A. J., and Gedye, J. L. (1961). Some supraspinal factors influencing generalised muscle activity. In Proc. Symposium on Skeletal Muscle Spasm, Riker Laboratories, pp. 31-50. Franklyn Ward and Wheeler, Leicester.

Berger, F. M. (1947). The mode of action of myanesin. Brit. J. Pharmacol., 2, 241-250.

- (1949). Spinal cord depressant drugs. Pharmacol. Rev., 1, 243-278.

Bowditch, H. P., and Warren, J. W. (1890). The knee-jerk and its physiological modifications. J. Physiol. (Lond.), 11, 25-64.

Buchwald, J. S., and Eldred, E. (1961). Relations between gamma efferent discharge and cortical activity. Electroenceph. clin. Neurophysiol., 13, 243-247.

Buller, A. J., and Dornhorst, A. C. (1957). The reinforcement of tendon-reflexes. Lancet, 2, 1260-1262. 
Clare, M. H., and Landau, W. M. (1964). Fusimotor function. Part V. Reflex reinforcement under fusimotor block in normal subjects. Arch. Neurol. (Chic.), 10, 123-127.

Clarke, A. M. (1965a). Specifications and characteristics of a soundproofed, electrically shielded and thermally insulated room. Aust. J. Psychol., 17, 124-132.

- (1965b). Relationship between the electromyogram and the force of the isometric reflex response of normal human subjects Nature (Lond.), 208, 551-552.

- (1966). The effect of stimulation of certain skin areas on the extensor motoneurons in the phasic reaction of a stretch reflex in normal human subjects. Electroenceph. clin. Neurophysiol., 21, 185-193.

Domino, E. F. (1956). The correlation between animal testing procedures and clinical effectiveness of centrally acting muscle relaxants of the mephenesin type. Ann. N.Y. Acad. Sci., 64, 705-729.

Eldred, E. (1960). Posture and locomotion. In Handbook of Physiology. Sect. I. Neurophysiology, Vol. 2, edited by J. Field, H. W. Magoun, and V. E. Hall, pp. 1067-1088. American Physiological Society. Washington.

- Granit, R., and Merton, P. A. (1953). Supraspinal control of the muscle spindles and its significance. J. Physiol. (Lond.), 122, 498-523.

muscle spindle activation. In Reticular Formation of the Brain, edited by H. H. Jasper et al., pp. 275-283. Little, Brown, Boston. [Henry Ford Hospital International Symposium.]

Granit, R. (1957). Systems for control of movement. C.R.I. Congr. int. Sci. neurol., Bruxelles, pp. 63-80.

- and Henatsch, H. D. (1956). Gamma control of dynamic properties of muscle spindles. J. Neurophysiol., 19, 356-366.

- , and Kaada, B. R. (1953). Influence of stimulation of central nervous structures on muscle spindles in cat. Acta physiol. scand., 27, 130-160.

_, Pompeiano, O., and Waltman, B. (1959). Fast supraspinal control of mammalian muscle spindles: extra- and intrafusal, co-activation. J. Physiol. (Lond.), 147, 385-398.
Homma, S., Kano, M., and Takano, K. (1962). On phasic stretch of the annulospiral ending. In Symposium on Muscle Receptors, edited by D. Barker, pp. 125-131. Hong Kong University Press.

Jacobson, E. (1924). The technic of progressive relaxation. J. nerv. ment. Dis., 60, 568-578.

Kuffler, S. W., Hunt, C. C., and Quilliam, J. P. (1951). Function of medullated small-nerve fibers in mammalian ventral roots: efferent muscle spindle innervation. J. Neurophysiol., 14, 29-54.

Landau, W. M., and Clare, M. H. (1964). Fusimotor function. Part IV. Reinforcement of the $\mathrm{H}$ reflex in normal subjects. Arch. Neurol. (Chic.), 10, 117-122.

Magoun, H. W. (1958). Non-specific brain mechanisms. In Biological and Biochemical Bases of Behavior, edited by H. F. Harlow and C. N. Woolsey, pp. 25-36. University of Wisconsin Press, Madison.

Matthews, P. B. C., and Rushworth, G. (1957). The selective effect of procaine on the stretch reflex and tendon jerk of soleus muscle when applied to its nerve. J. Physiol. (Lond.), 135, 245-262.

Paillard, J. (1959). Functional organization of afferent innervation of muscle studied in man by monosynaptic testing. Amer. $J$. phys. Med., 38, 239-247.

Rabending, G., and Koch, R. D. (1962). Influence of the amplitude of monosynpatic reflexes on the duration of the silent period. Electroenceph. clin. Neurophysiol., suppl., 22, [Progress in Electromyography] pp. 120-121.

Rossi, G. F., and Zanchetti, A. (1957). The brain stem reticular formation. Anatomy and physiology. Arch. ital. Biol., 95, 199-435.

Sink, J. D. (1965). Effect of mephenesin on skeletal muscle myofibrils. Experientia, 21, 654-655.

Varnum, W. (1934). Factors influencing the latent time of the patellar reflex. J. exp. Psychol., 17, 556-573.

Voorhoeve, P. E. (1960). Autochthonous activity of fusimotor neurones in the cat. Acta physiol. pharmacol. neerl., 9, 1-43. 